\title{
Distinct Clinical Courses of Epithelial Ovarian Cancer with Mutations in BRCA1 5' and 3' Exons
}

\author{
KYUNG JIN EOH ${ }^{1}$, HYUNG SEOK PARK ${ }^{2,3}$, JI SOO PARK ${ }^{2,4}$, SEUNG-TAE LEE ${ }^{2,5}$, JUNG WOO HAN ${ }^{2,6}$, \\ JUNG-YUN LEE ${ }^{1}$, SUNGHOON KIM ${ }^{1}$, SANG WUN KIM ${ }^{1}$, YOUNG TAE KIM ${ }^{1}$ and EUN JI NAM ${ }^{1,2}$ \\ ${ }^{1}$ Institute of Women's Life Medical Science, Women's Cancer Center, Department of Obstetrics and Gynecology, \\ Yonsei University College of Medicine, Seoul, Republic of Korea; \\ ${ }^{2}$ Hereditary Cancer Clinic of Cancer Prevention Center, Yonsei Cancer Center, Severance Hospital, \\ Yonsei University College of Medicine, Seoul, Republic of Korea, \\ ${ }^{3}$ Department of Surgery, Yonsei University College of Medicine, Seoul, Republic of Korea; \\ ${ }^{4}$ Cancer Prevention Center, Yonsei Cancer Center, Seoul, Republic of Korea; \\ ${ }^{5}$ Department of Laboratory Medicine, Yonsei University College of Medicine, Seoul, Republic of Korea; \\ ${ }^{6}$ Department of Pediatrics, Yonsei University College of Medicine, Seoul, Republic of Korea
}

\begin{abstract}
Background/Aim: This study aimed to determine the effect of different BRCAl exonal mutations on the clinical course of epithelial ovarian cancer (EOC). Patients and Methods: Clinicopathological variables and survival outcomes were compared among 53 primary EOC patients with pathogenic BRCAl mutations in exons $1-11$ (5' mutations) and in exons 12-24 (3' mutations). Results: BRCA1 5' exonal mutations were found in 35 (66.0\%) patients. The median follow-up period was 40 months. Clinicopathological variables remained unchanged between the two groups. Patients with 5' mutations had a significantly longer progression-free survival than those with $C$-terminal mutations $(p=0.034)$, better predicting progression-free survival [2.923 (1.402-6.093), $p=0.004]$, but not overall survival in cases of multiple relapses $(p=0.497)$. Conclusion: $N$-terminal BRCA1 mutations in EOC patients are associated with favourable primary progression-free survival, a trend observed only in primary progression-free survival, not in overall survival.
\end{abstract}

Epithelial ovarian cancer (EOC) remains a gynaecologic malignancy with the highest mortality, with over two-thirds of patients diagnosed at advanced stages of the disease (1). Approximately $10 \%$ of cases are due to an inherited predisposition, and a large fraction of the inheritance is

Correspondence to: Eun Ji Nam, MD, Ph.D., Department of Obstetrics and Gynecology, Yonsei University College of Medicine, 50-1, Yonsei-ro, Seodaemun-gu, Seoul 03722, Republic of Korea. Tel: +82 222282250, Fax: +82 23138350, e-mail: NAHMEJ6@yuhs.ac

Key Words: BRCA1, epithelial ovarian cancer, exon, prognosis. attributable to mutations in $B R C A 1 / 2$ (2). Several previous studies have reported that germline mutations in $B R C A l$ and $B R C A 2$ are correlated with a favourable prognosis, probably owing to the high response rate of their carriers to platinumbased chemotherapy (3-7).

However, conclusive evidence on BRCAl-associated prognosis in EOC patients is lacking because of inconsistent data on the survival advantage of mutated carriers compared to non-mutated patients, particularly regarding long-term follow-up $(8,9)$. Moreover, the results of these studies do not consider the location of the mutated exon within BRCAl.

$B R C A l$ contains 24 exons encoding a large protein of 1,863 amino acid residues (10). However, limited information is available regarding the clinical effects of mutations located in different BRCAl exons on EOC onset and progression (11). The available evidence allows the assumption that mutations in different $B R C A l$ gene sites may differentially affect the clinical course of ovarian cancer disease $(12,13)$. Therefore, in the present study, the clinical impact of $B R C A 1$ mutations located in the first 11 exons was compared with that of mutations located in the last 13 exons, with a focus on clinicopathological characteristics and survival outcomes.

\section{Materials and Methods}

Patient selection and pathologic review. The study protocol was approved by the Institutional Review Board of the Yonsei University College of Medicine (No. 4-2017-0564), and the study was performed in accordance with the ethical standards described in the Declaration of Helsinki. Informed consent was waived by the Institutional Review Board of the Yonsei University College of Medicine because of the retrospective nature of the study that based on medical records, and the fact that this research presented no more than minimal risk of 
Table I. Clinicopathological characteristics of patients.

\begin{tabular}{|c|c|c|c|c|}
\hline \multirow[t]{2}{*}{ Variables } & \multirow[t]{2}{*}{ Total $(\mathrm{n}=53)$} & \multicolumn{2}{|c|}{ Mutated exon level } & \multirow[b]{2}{*}{$p$-Value } \\
\hline & & Exon number $\leq 11 \quad(n=35)$ & Exon number $>11 \quad(n=18)$ & \\
\hline Age at diagnosis, year & $49(27-77)$ & $49(28-77)$ & $52.5(27-72)$ & 0.11 \\
\hline Family history & $23(43.4)$ & $14(40.0)$ & $9(50.0)$ & 0.242 \\
\hline Breast cancer history & $21(39.6)$ & $12(34.3)$ & $9(50.0)$ & \\
\hline \multicolumn{5}{|l|}{ Histology } \\
\hline Serous & $52(98.1)$ & $35(100.0)$ & $17(94.4)$ & 0.159 \\
\hline Endometrioid & $1(1.9)$ & 0 & $1(5.6)$ & \\
\hline \multicolumn{5}{|l|}{ Stage } \\
\hline Early $(1,2)$ & $4(7.5)$ & $2(5.7)$ & $2(11.1)$ & 0.481 \\
\hline Advanced $(3,4)$ & $49(92.5)$ & $33(94.3)$ & $16(88.9)$ & \\
\hline \multicolumn{5}{|l|}{ Grade } \\
\hline Low & $1(1.9)$ & 0 & $1(5.6)$ & 0.222 \\
\hline High & $52(98.1)$ & $35(100.0)$ & $17(94.4)$ & \\
\hline Peritoneal carcinomatosis & $29(54.7)$ & $22(62.9)$ & $7(38.9)$ & 0.097 \\
\hline $\mathrm{CA} 125 \geq 500 \mathrm{U} / \mathrm{ml}$ & $32(60.4)$ & $22(62.9)$ & $12(66.7)$ & \\
\hline NAC & $12(22.6)$ & $6(17.6)$ & $6(33.3)$ & 0.3 \\
\hline \multicolumn{5}{|l|}{ Residual disease } \\
\hline NGR & $26(49.1)$ & $15(42.9)$ & $11(61.1)$ & 0.537 \\
\hline$<0.5 \mathrm{~cm}$ & $17(32.1)$ & $12(34.3)$ & $5(27.8)$ & \\
\hline$<1.0 \mathrm{~cm}$ & $7(13.2)$ & $6(17.1)$ & $1(5.6)$ & \\
\hline$<2.0 \mathrm{~cm}$ & $3(5.7)$ & $2(5.7)$ & $1(5.6)$ & \\
\hline
\end{tabular}

NAC: Neoadjuvant chemotherapy; NGR: no gross residual disease.

harm to subjects. EOC patients with $B R C A 1$ mutations were included in the analysis. Upon reviewing their medical records, data regarding several characteristics of the patients, including age at diagnosis, histological type (from pathology reports), and surgical stage in accordance with the International Federation of Gynecology and Obstetrics (FIGO) criteria were obtained. A homogeneous regimen (i.e. paclitaxel and carboplatin) was administered as postoperative adjuvant chemotherapy six times in cases involving primary debulking surgery and of postoperative adjuvant chemotherapy thrice followed by six times in cases involving neoadjuvant chemotherapy. The patients were divided into two groups on the basis of the location of the mutated exon in BRCA1. The mutation was defined as 5, BRCA1 mutation if it occurred in exons 1-11, and as a $3^{\prime}$ BRCAl mutation if it occurred in exons 12-24. Clinicopathological variables and survival outcomes in patients with mutations in exons 1-11 (5, mutations) were compared to those in patients with mutations in exons 12-24 (5'nal mutations). Exon 11 was considered to represent the central region of $B R C A 1$. Platinum sensitivity was defined as the maintenance of complete remission for 12 months or more after the completion of frontline chemotherapy.

Direct sequencing. Genetic testing for BRCAl (accession number NM_007294) mutations was performed via direct sequencing, as described previously (14). Genetic mutations analysed herein were confined to deleterious mutations, such as frameshift or nonsense mutations. Variations were described in accordance with the nomenclature system of the Human Genome Variation Society (http://www.hgvs.org/mutnomen) and the conventional nomenclature system from the Breast Cancer Information Core (BIC; http://research.nhgri.nih.gov/bic/).
Statistical analysis. Statistical analysis was performed using IBM SPSS version 23.0 for Windows (SPSS Inc., Chicago, IL, USA). Pearson's chi-squared test, Fisher's exact test, and Mann-Whitney $U$-test were performed for univariate analysis. Survival outcomes were determined via Kaplan-Meier survival analysis. First progression-free survival (PFS) was defined as the interval between the date of initiation of treatment and the date of documented disease progression or death from any cause. Second and third PFSs were defined as the intervals between the date of termination of prior treatment and the date of documented disease progression or death from any cause. Overall survival (OS) was defined as the interval between the date of initiation of treatment and the date of death due to any cause. Patients lost to follow-up were censored at the last date of contact. Univariate and multivariate analyses of the effects of various prognostic factors on survival were performed using the Cox proportional hazards model. Multivariate analysis was carried out using variables with $p$-Value less than 0.1 in the univariate analysis.

\section{Results}

Patient characteristics. Patient characteristics are enlisted in Table I. In total, 53 EOC patients with BRCAl mutations were included. The distribution of mutations in exons is presented in Figure 1. Mutations in BRCAl exons 1-11 were present in 35 of the 53 patients $(66.0 \%)$, whereas mutations in BRCA1 exons $12-24$ were observed in 18 patients $(34.0 \%)$. There were no significant differences in clinicopathological variables, including age at diagnosis, family history of cancer, breast 


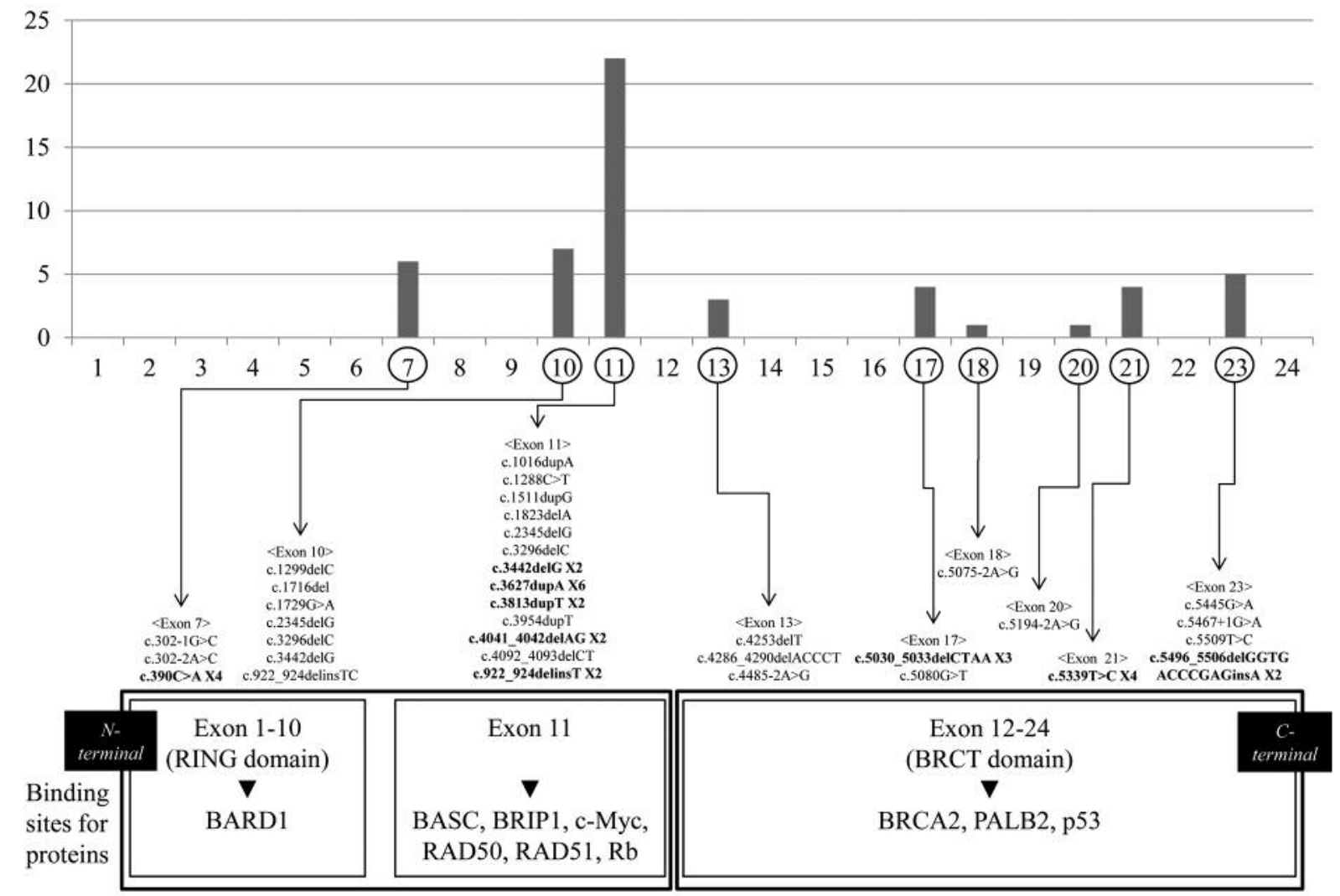

Figure 1. Distribution of mutations in BRCA1 exons in ovarian cancer patients and reported binding sites for proteins (20). Data in boldface indicate repeated detection.

cancer history, histology, grade, FIGO stage, peritoneal carcinomatosis, CA125 higher than 500, the decision of whether to administer neoadjuvant chemotherapy, or residual disease after debulking surgery in patients with $\mathrm{N}$-terminal mutations and those with C-terminal BRCAl mutations.

Sensitivity to chemotherapy. The proportion of patients displaying chemosensitivity is presented in Figure 2. The presence of a germline mutation in BRCAl exons 1-11 was closely associated with primary chemotherapy sensitivity, with a relative risk (RR) of 1.43 [95\% confidence interval $(C I)=1.082-2.079]$. However, the ability of genetic alterations to predict responses to chemotherapy was lost in the second and third rounds of chemotherapy, with RR of 0.947 $(95 \% \mathrm{CI}=0.385-2.332)$ and $\mathrm{RR}$ of $1.061(95 \% \mathrm{CI}=0.363-3.101)$, respectively.

Survival analysis. The median follow-up period was 40 months. Kaplan-Meier survival analysis revealed significantly improved PFS in patients with 5' BRCAl mutations in exons 1-11 compared with that in patients with 3 ' BRCAl mutation in exons 12-24 ( $p=0.034$, Figure $3 \mathrm{~A})$. However, the tendency of favourable outcomes was not observed in patients experiencing multiple relapses (Figure $3 \mathrm{~B}$ and $\mathrm{C}$ ). In particular, no significant difference in OS was observed between the two groups of patients ( $p=0.497$, Figure 3D). The presence of a 5' BRCAl mutation was found to be one of the significant predictive factors for PFS upon Cox regression multivariate analysis [2.923 (1.402-6.093), $p=0.004]$ and upon univariate analysis [3.865 (1.583-9.439), $p=0.003$ ], as was the residual disease after debulking surgery [2.267 (1.065-4.829), $p=0.034]$ (Table II).

\section{Discussion}

The present study aimed to assess the clinical impact of mutations in the BRCAl gene depending on the mutation site. The results indicate that EOC patients with mutations at the 5' and 3' parts of the BRCAl gene (exons 1-11 and 1224 , respectively) did not differ with respect to their clinicopathologic variables, including optimal debulking rate and FIGO stage. However, the first chemotherapy response rate and first PFS were significantly higher in patients with 5' BRCAl mutations. This trend was not observed after 


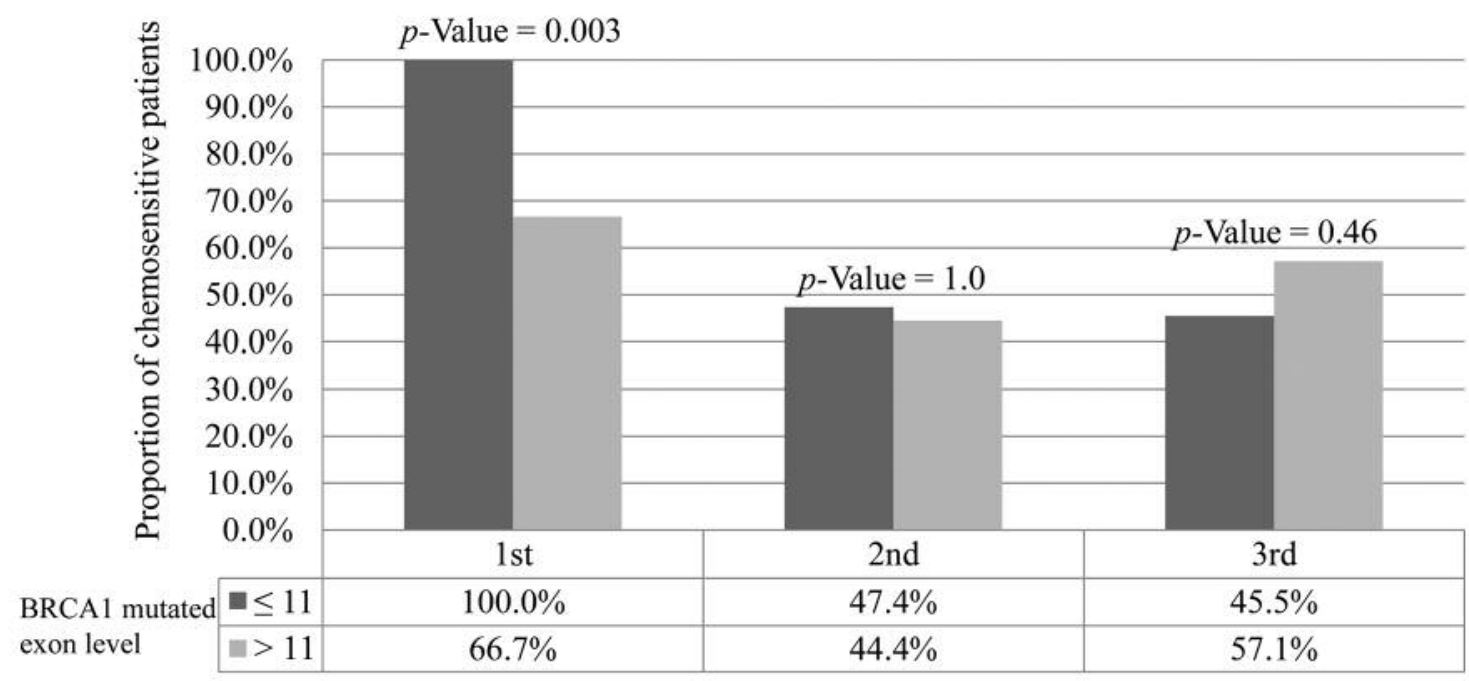

Figure 2. Proportion of patients displaying chemosensitivity.

A

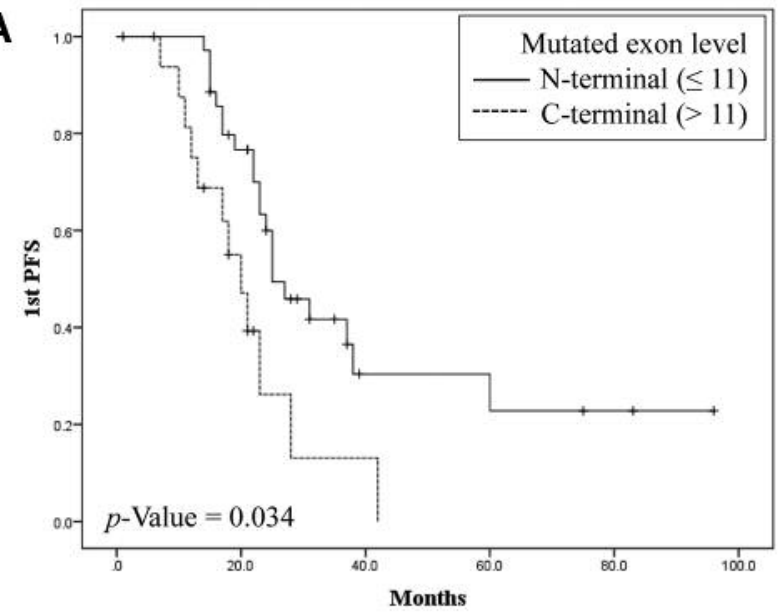

C

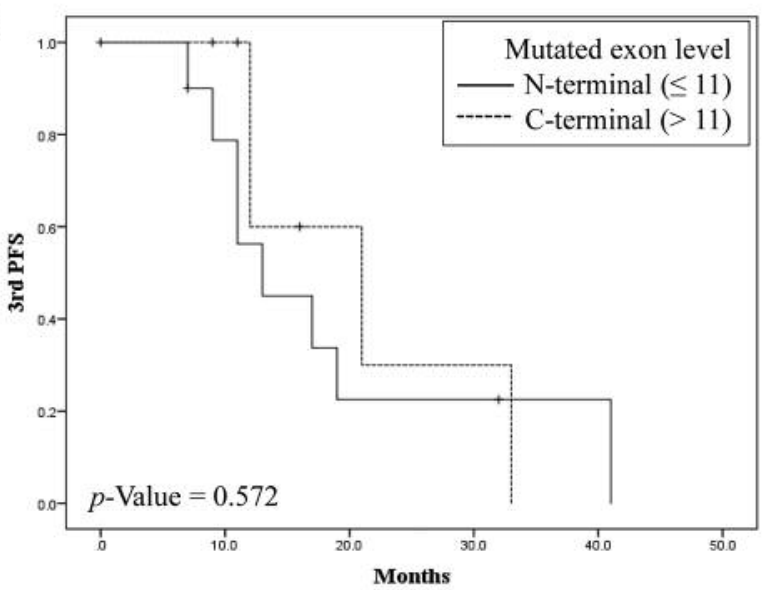

B

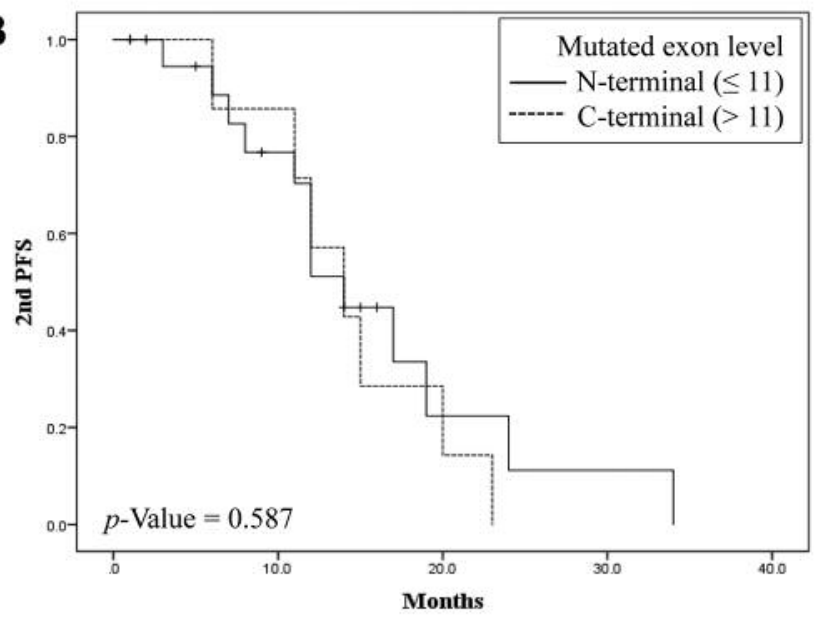

D

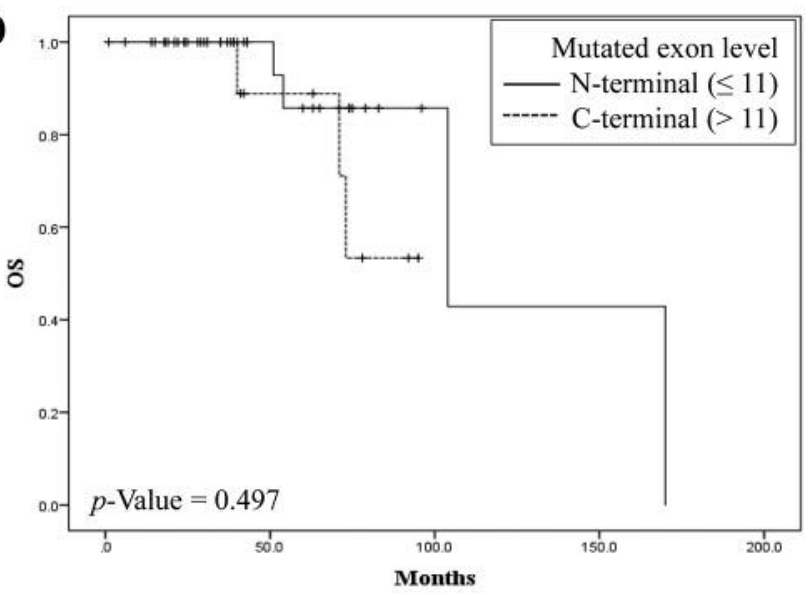

Figure 3. Comparison of the 1st PFS (A), 2nd PFS (B), 3rd PFS (C), and OS (D) in groups of patients with 5' and 3' BRCA1 exon mutations. PFS: Progression-free survival; OS: overall survival. 
Table II. Univariate and multivariate analyses of prognostic factors for progression-free survival.

\begin{tabular}{|c|c|c|c|c|c|}
\hline & \multirow[t]{3}{*}{ No. of patients } & \multicolumn{4}{|c|}{ PFS } \\
\hline & & \multicolumn{2}{|c|}{ Univariate analysis } & \multicolumn{2}{|c|}{ Multivariate analysis } \\
\hline & & HR $(95 \% \mathrm{CI})$ & $p$-Value & HR $(95 \% \mathrm{CI})$ & $p$-Value \\
\hline Age, years (continuous) & 53 & $0.993(0.955-1.032)$ & 0.724 & & \\
\hline \multicolumn{6}{|l|}{ Stage } \\
\hline Advanced & 49 & 1 (Reference) & & & \\
\hline Early & 4 & $0.527(0.098-2.844)$ & 0.327 & & \\
\hline \multicolumn{6}{|c|}{ Preoperative CA $125, \mathrm{U} / \mathrm{ml}$} \\
\hline$\leq 500$ & 21 & 1 (Reference) & & & \\
\hline$>500$ & 32 & $1.488(0.666-3.327)$ & 0.333 & & \\
\hline \multicolumn{6}{|l|}{ Peritoneal carcinomatosis } \\
\hline No & 24 & 1 (Reference) & & & \\
\hline Yes & 29 & $1.542(0.624-3.813)$ & 0.348 & & \\
\hline \multicolumn{6}{|l|}{ Breast cancer history } \\
\hline No & 32 & 1 (Reference) & & & \\
\hline Yes & 21 & $0.940(0.421-2.101)$ & 0.88 & & \\
\hline \multicolumn{6}{|l|}{ Cancer family history } \\
\hline No & 30 & 1 (Reference) & & & \\
\hline Yes & 23 & $0.858(0.386-1.910)$ & 0.708 & & \\
\hline \multicolumn{6}{|l|}{ NAC } \\
\hline No & 41 & 1 (Reference) & 0.454 & & \\
\hline Yes & 12 & $0.489(0.091-2.636)$ & & & \\
\hline \multicolumn{6}{|l|}{ Residual disease } \\
\hline NGR & 26 & 1 (Reference) & & 1 (Reference) & \\
\hline Non-NGR & 27 & $2.243(0.963-5.224)$ & 0.061 & $2.267(1.065-4.829)$ & 0.034 \\
\hline \multicolumn{6}{|l|}{ Mutated exon level } \\
\hline$\leq 11(\mathrm{~N}$-terminal $)$ & 35 & 1 (Reference) & & 1 (Reference) & \\
\hline$>1$ (C-terminal) & 18 & $3.865(1.583-9.439)$ & 0.003 & $2.923(1.402-6.093)$ & 0.004 \\
\hline
\end{tabular}

PFS: Progression-free survival; HR: hazard ratio; CI: confidential interval; NAC: neoadjuvant chemotherapy; NGR: no gross residual disease.

multiple relapses and in the OS. With accurate validation, these data may have implications for decision making related to risk assessment and cancer prevention during the treatment of patients harbouring $B R C A l$ mutations.

Although the clinical role of $B R C A l$ germline mutations has been investigated in detail in EOC patients, comprehensive data regarding the association between the location of $B R C A 1$ mutations and the natural course of EOC are still wanted. We hypothesized that mutations in different $B R C A l$ exons might differentially affect the response to double-strand break (DSB)inducing agents. Our results suggest that mutations in 5' exons might result in a lower residual function of the BRCA1 protein compared with those in 3 ' exons.

The effect of different BRCAl gene mutation sites on patient prognosis has been reported previously (13). However, contrary to our results, the previous study reported that 5' BRCA1 mutations correlated with decreased survival, whereas 3' mutations were associated with increased survival. Concurrent with those findings, another recent study reported that mutations in the RING-type zinc finger domain (5') of $B R C A 1$ confer poor responsiveness to cisplatin and poly ADP ribose polymerase inhibitors (12). In the present study, we observed that 5 ' mutations in exons $1-11$ of the BRCAl gene result in decreased residual activity of the BRCA1 protein, seemingly correlating with an increased response rate to cytotoxic chemotherapy. However, this trend was not observed after multiple recurrences. This discrepancy warrants further analysis in studies with larger samples.

DSBs are the most cytotoxic forms of DNA damage (15). In addition, homologous recombination (HR) deficiency is known to underlie the hypersensitivity of BRCAl-deficient cells to DNA DSB-inducing agents (16). Although patients with $B R C A 1$-associated EOC are often sensitive to platinum-based chemotherapy, they eventually develop chemoresistance through secondary mutations in $B R C A 1$, which restore its function (17). It is unclear which functions of $B R C A l$ confer chemotherapeutic resistance; however, the reversion of $B R C A l$ germline mutations has been observed in resistant tumors (18).

BRCA1 is a large protein that comprises four domains required for heterodimerization of BRCA1 and numerous HR-related enzymes, including BARD1, BRIP1, the RAD family, PALB2, and BRCA2 (Figure 1) (19). Our 
observations are concurrent with the concept that once a mutation in BRCAl has occurred, residual gene function of $B R C A 1$ might be a critical factor for the repair process. Mutations in different exons may produce differential effects on the clinical course of EOC by altering interactions of BRCA1 with various types of HR-related enzymes.

One of the most remarkable findings of the present study is that the difference in the fraction of chemosensitive patients and in the tendency of favourable primary PFS was obliterated in patients experiencing multiple relapses. The trend of favourable outcomes of BRCA1-associated EOC patients is reportedly lost in long-term follow-up periods ( 9 , 20). This might be explained by the reversal of BRCAl mutations observed in recurrent cancer tissue, which is assumed to be a resistance mechanism (21). According to our data, we assumed that 5' mutations in exons 1-11 of BRCAl appeared prone to reversal in multiple relapses, thereby resulting in chemoresistance. This hypothesis warrants further validation with sequential biopsy for the analysis of somatic mutations in future studies.

One limitation of the present study is that the assessments were performed in a small cohort in a retrospective manner. Furthermore, clinical effects of all types of mutations in $B R C A l$ were assessed. However, to our knowledge, this is the first study based on the concept that exon location may influence the clinical course of BRCAl-associated EOC. Moreover, EOC patients were treated similarly at a single institution, and the prevention of a potential bias, including the exclusion of patients with BRCA2 mutations, can be highlighted as a strength of the present study.

In summary, 5' mutations in BRCAl in exons 1-11 apparently confer a more favourable primary PFS in EOC patients with a higher response rate to chemotherapy. However, this trend of favourable prognosis was observed only in primary PFS. For personalized medicine, future studies on BRCAl gene mutations should focus on the clinical features of different types of mutations, particularly their location on different exons. This process might enable selection of patients with BRCAl mutations benefitting maximally from treatment with new targeted therapies, including those involving poly ADP ribose polymerase inhibitors. Such studies will also provide access to new drugs in a more cost-effective manner.

\section{Conflicts of Interest}

The Authors have no financial conflicts of interest to disclose regarding this study.

\section{Acknowledgements}

This study was supported by the Basic Science Research Program through the National Research Foundation of Korea funded by the Ministry of Science, ICT \& Future Planning (2014R1A1A1
A05002926 2017R1A2B4005503) and Faculty Research Grant of Yousei University College of Medicine (6-2018-0053). The funding body did not influence the study design, collection, analysis, or interpretation of data.

\section{References}

1 Siegel RL, Miller KD and Jemal A: Cancer statistics, 2015. CA Cancer J Clin 65(1): 5-29, 2015.

2 Ramus SJ and Gayther SA: The contribution of brca1 and brca2 to ovarian cancer. Mol Oncol 3(2): 138-150, 2009.

3 Cass I, Baldwin RL, Varkey T, Moslehi R, Narod SA and Karlan BY: Improved survival in women with brca-associated ovarian carcinoma. Cancer 97(9): 2187-2195, 2003.

4 Tan DS, Rothermundt C, Thomas K, Bancroft E, Eeles R, Shanley S, Ardern-Jones A, Norman A, Kaye SB and Gore ME: "Brcaness" syndrome in ovarian cancer: A case-control study describing the clinical features and outcome of patients with epithelial ovarian cancer associated with brca1 and brca2 mutations. J Clin Oncol 26(34): 5530-5536, 2008.

5 Harter P, Johnson T, Berton-Rigaud D, Park SY, Friedlander M, Del Campo JM, Shimada M, Forget F, Mirza MR, Colombo N, Zamagni C, Chan JK, Imhof M, Herzog TJ, O'Donnell D, Heitz F, King K, Stinnett S, Barrett C, Jobanputra M, Xu CF and du Bois A: Brca1/2 mutations associated with progression-free survival in ovarian cancer patients in the ago-ovar 16 study. Gynecol Oncol 140(3): 443-449, 2016.

6 Eoh KJ, Park HS, Park JS, Lee ST, Han J, Lee JY, Kim SW, Kim S, Kim YT and Nam EJ: Comparison of clinical outcomes of brca1/2 pathologic mutation, variants of unknown significance, or wild type epithelial ovarian cancer patients. Cancer Res Treat 49(2): 408-415, 2017.

7 Yang D, Khan S, Sun Y, Hess K, Shmulevich I, Sood AK and Zhang W: Association of brca1 and brca2 mutations with survival, chemotherapy sensitivity, and gene mutator phenotype in patients with ovarian cancer. JAMA 306(14): 1557-1565, 2011.

8 Chetrit A, Hirsh-Yechezkel G, Ben-David Y, Lubin F, Friedman E and Sadetzki S: Effect of brca1/2 mutations on long-term survival of patients with invasive ovarian cancer: The national israeli study of ovarian cancer. J Clin Oncol 26(1): 20-25, 2008.

9 Kotsopoulos J, Rosen B, Fan I, Moody J, McLaughlin JR, Risch H, May T, Sun P and Narod SA: Ten-year survival after epithelial ovarian cancer is not associated with brca mutation status. Gynecol Oncol 140(1): 42-47, 2016.

10 Marquis ST, Rajan JV, Wynshaw-Boris A, Xu J, Yin GY, Abel KJ, Weber BL and Chodosh LA: The developmental pattern of brca1 expression implies a role in differentiation of the breast and other tissues. Nat Genet 11(1): 17-26, 1995.

11 Dimitrova D, Ruscito I, Olek S, Richter R, Hellwag A, Turbachova I, Woopen H, Baron U, Braicu EI and Sehouli J: Germline mutations of brca1 gene exon 11 are not associated with platinum response neither with survival advantage in patients with primary ovarian cancer: Understanding the clinical importance of one of the biggest human exons. A study of the tumor bank ovarian cancer (toc) consortium. Tumour Biol 37(9): 12329-12337, 2016.

12 Drost R, Bouwman P, Rottenberg S, Boon U, Schut E, Klarenbeek S, Klijn C, van der Heijden I, van der Gulden H, Wientjens E, Pieterse M, Catteau A, Green P, Solomon E, Morris JR and Jonkers $\mathrm{J}$ : Brca1 ring function is essential for tumor 
suppression but dispensable for therapy resistance. Cancer Cell 20(6): 797-809, 2011.

13 Bolton KL, Chenevix-Trench G, Goh C, Sadetzki S, Ramus SJ, Karlan BY, Lambrechts D, Despierre E, Barrowdale D, McGuffog L, Healey S, Easton DF, Sinilnikova O, Benitez J, Garcia MJ, Neuhausen S, Gail MH, Hartge P, Peock S, Frost D, Evans DG, Eeles R, Godwin AK, Daly MB, Kwong A, Ma ES, Lazaro C, Blanco I, Montagna M, D’Andrea E, Nicoletto MO, Johnatty SE, Kjaer SK, Jensen A, Hogdall E, Goode EL, Fridley BL, Loud JT, Greene MH, Mai PL, Chetrit A, Lubin F, HirshYechezkel G, Glendon G, Andrulis IL, Toland AE, Senter L, Gore ME, Gourley C, Michie CO, Song H, Tyrer J, Whittemore AS, McGuire V, Sieh W, Kristoffersson U, Olsson H, Borg A, Levine DA, Steele L, Beattie MS, Chan S, Nussbaum RL, Moysich KB, Gross J, Cass I, Walsh C, Li AJ, Leuchter R, Gordon O, Garcia-Closas M, Gayther SA, Chanock SJ, Antoniou AC, Pharoah PD, Embrace, kConFab I and Cancer Genome Atlas Research N: Association between brca1 and brca2 mutations and survival in women with invasive epithelial ovarian cancer. JAMA 307(4): 382-390, 2012.

14 Kim YT, Nam EJ, Yoon BS, Kim SW, Kim SH, Kim JH, Kim HK, Koo JS and Kim JW: Germline mutations of brca1 and brca2 in korean sporadic ovarian carcinoma. Gynecol Oncol 99(3): 585-590, 2005.

15 Huertas P: DNA resection in eukaryotes: Deciding how to fix the break. Nat Struct Mol Biol 17(1): 11-16, 2010.

16 Bhattacharyya A, Ear US, Koller BH, Weichselbaum RR and Bishop DK: The breast cancer susceptibility gene brca1 is required for subnuclear assembly of rad51 and survival following treatment with the DNA cross-linking agent cisplatin J Biol Chem 275(31): 23899-23903, 2000.
17 Swisher EM, Sakai W, Karlan BY, Wurz K, Urban N and Taniguchi T: Secondary brcal mutations in brca1-mutated ovarian carcinomas with platinum resistance. Cancer Res 68(8): 2581-2586, 2008.

18 Christie EL, Fereday S, Doig K, Pattnaik S, Dawson SJ and Bowtell DDL: Reversion of brca1/2 germline mutations detected in circulating tumor DNA from patients with high-grade serous ovarian cancer. J Clin Oncol 35(12): 1274-1280, 2017.

19 van der Groep P, van der Wall E and van Diest PJ: Pathology of hereditary breast cancer. Cell Oncol (Dordr) 34(2): 71-88, 2011.

20 McLaughlin JR, Rosen B, Moody J, Pal T, Fan I, Shaw PA, Risch HA, Sellers TA, Sun P and Narod SA: Long-term ovarian cancer survival associated with mutation in brca1 or brca2. J Natl Cancer Inst 105(2): 141-148, 2013.

21 Lheureux S, Bruce JP, Burnier JV, Karakasis K, Shaw PA, Clarke BA, Yang SY, Quevedo R, Li T, Dowar M, Bowering V, Pugh TJ and Oza AM: Somatic brca1/2 recovery as a resistance mechanism after exceptional response to poly (adp-ribose) polymerase inhibition. J Clin Oncol 35(11): 1240-1249, 2017.

Received October 17, 2018

Revised October 29, 2018

Accepted October 31, 2018 